\title{
Effect of a diet containing folate and hazelnut oil capsule on the methylation level of the ADRB3 gene, lipid profile and oxidative stress in overweight or obese women
}

Raquel Patrícia Ataíde Lima ${ }^{1,10^{*}}$, Rayner Anderson Ferreira do Nascimento ${ }^{2}$, Rafaella Cristhine Pordeus Luna ${ }^{3}$, Darlene Camati Persuhn ${ }^{4}$, Alexandre Sérgio da Silva ${ }^{3}$, Maria da Conceição Rodrigues Gonçalves ${ }^{3}$,

Alessio Tony Cavalcanti de Almeida ${ }^{5}$, Ronei Marcos de Moraes ${ }^{6}$, Eliseu Verly Junior ${ }^{7}$, Emmanuelle Fouilloux-Meugnier ${ }^{8}$, Hubert Vidal $^{8}$, Luciano Pirola ${ }^{8}$, Marciane Magnani ${ }^{3}$, Naila Francis Paulo de Oliveira ${ }^{4}$, Patrícia Oliveira Prada ${ }^{9}$ and Maria José de Carvalho Costa ${ }^{3}$

\begin{abstract}
Background: Studies of genes that play an important role in the development of obesity are needed, especially studies focusing on genes that regulate food intake and affect nutrient metabolism. For example, the beta-3 adrenergic receptor (ADRB3) responds to noradrenaline and mediates lipolysis in adipocytes.

Methods: This was a controlled intervention study involving 40 overweight and obese adult women in which food intake, anthropometric measurements, biochemical analyses, and methylation levels of the ADRB3 gene were evaluated before and after intervention. The individuals were randomized into four groups: group 1 (G1) received $300 \mathrm{~g}$ of vegetables and legumes containing on average $191 \mu \mathrm{g} /$ day of folate and 1 hazelnut oil capsule; group 2 (G2) received $300 \mathrm{~g}$ of vegetables and legumes containing on average $191 \mu \mathrm{g} /$ day of folate and 1 placebo capsule; group 3 (G3) received $300 \mathrm{~g}$ of vegetables and legumes containing on average $90 \mathrm{\mu g} / \mathrm{day}$ of folate and 1 hazelnut oil capsule; and individuals in group 4 (G4) were only followed-up and maintained their regular dietary habits. Statistical analysis was performed using analysis of variance (ANOVA), Student's $t$ test and simple regression, using STATA 13 software.
\end{abstract}

Results: In the total sample, after the intervention, the women classified as overweight and obese did not present weight loss, and there was a reduction in the methylation levels of the ADRB3 gene and malondialdehyde, as well as an increase in high-density lipoprotein cholesterol and total antioxidant capacity.

(Continued on next page)

\footnotetext{
* Correspondence: raquelpatriciaal@hotmail.com

'Graduate Program in Nutritional Sciences, Health Sciences Center (Centro de Ciências da Saúd-CCS), Federal University of Paraíba (Universidade Federal da Paraíba), João Pessoa, Brazil

${ }^{10}$ Present Address: Pós-graduação em Ciências da Nutrição, Centro de Ciências da Saúde, NIESN-Núcleo Interdisciplinar de Estudos em Saúde e Nutrição/Universidade Federal da Paraíba, Castelo Branco, João Pessoa, PB 58059-900, Brazil

Full list of author information is available at the end of the article
} 
(Continued from previous page)

Conclusions: The beneficial effect of the intake of a hazelnut capsule on the methylation levels of the ADRB3 gene was demonstrated for the first time.

Trial registration: ClinicalTrials.gov, NCT 02846025

Keywords: ADRB3, Obesity, DNA methylation, Biochemical analyses, Diet

\section{Background}

Obesity is a metabolic disease that is rapidly increasing around the world. Recent World Health Organization data show that over one third of adults over 18 years of age (38\% of men and $40 \%$ of women) are overweight, with women in all regions being more prone to obesity than men [1].

In recent decades, obesity has been considered a result of an imbalance between energy intake and expenditure that is driven by easy access to high-calorie foods and reduced energy expenditure [2].

Other factors related to the prevalence of obesity are sleep disorders, endocrine disorders, oxidative stress, inflammation, increased maternal age, microbiota, and genetics [3].

In addition to genetic factors, epigenetic mechanisms contribute to the unexplained inheritance of obesity and fat distribution [4]. These epigenetic changes have been associated with the effects of diet composition on health and disease or the long-term effects of gene-environment interactions [5, 6]. Folate is a nutrient known to participate in DNA methylation and nucleotide reactions of biosynthesis and is also involved in the formation of methyl groups, which serves as a methyl donor in DNA methylation. Another component that possibly modulates the epigenetic profile is fat and its fractions [4].

There are many important genes involved in the development of obesity whose expression is under the influence of epigenetic regulation. Recent studies have focused on evaluating changes in the methylation pattern of specific obesity-related genes.

DNA methylation represents one of the most important epigenetic mechanisms for regulating gene expression and is the most widely studied thus far. This mechanism involves the covalent attachment of a methyl group to the $5^{\prime}$ position of the cytosine present in the genome of the DNA sequence by DNA methyltransferases (DNMTs) [1]. This methylation is the only known modification that targets DNA itself and is generally associated with gene silencing [7].

There is increasing evidence that gene methylation may contribute to obesity. In fact, studies of the methylation of candidate genes in animal and human models have demonstrated methylation changes in promoters of several genes that are involved in obesity, appetite control, and/or metabolism [8], namely, the beta-3 adrenergic receptor $(A D R B 3)$, which responds to noradrenaline and mediates lipolysis in adipocytes [9].

In this context, the present study aims to evaluate the effect of a diet containing folate and hazelnut oil capsule on the methylation levels of the ADRB3 gene, lipid profile and oxidative stress in overweight and obese women.

\section{Methods \\ Study design}

This is a double-blind, placebo-controlled, intervention study linked to a population-based study titled "II Ciclo de Diagnóstico e Intervenção da Situação Alimentar, Nutricional e das Doenças não Transmissíveis mais Prevalentes da População do Município de João Pessoa/ PB (II DISANDNT/JP) [Cycle II of Diagnosis and Intervention of the Food, Nutritional and NonCommunicable Diseases Statuses of the Population of the Municipality of João Pessoa/PB (II DISANDNT/ JP)", which was conducted between May 2015 and May 2016. Participants were selected from the sample of overweight and obese adults with the following inclusion criteria.

The following women were included: adult women aged 20 to 59 years, who were overweight or obese (body mass index (BMI) $25.0-35.0 \mathrm{~kg} / \mathrm{m}^{2}$ ), with different socioeconomic levels, and who were users or non-users of medications and had a preserved cognitive status. The exclusion criteria included alcoholism, smoking, neuropsychiatric disorders, use of drugs known to interfere with folic acid metabolism (in the last 3 months), use of multivitamin or mineral supplements, use of anorexigenic substances or of anabolic substances, chronic diseases affecting the endocrine and metabolic system, pregnancy, plans to become pregnant, and loss of weight during the study period.

After screening, 40 adult female subjects were selected by convenience sampling and were properly instructed regarding the study objectives according to ethical guidelines; the subjects consented to participate by signing an informed consent form. The study was approved by the Research Ethics Committee of the CCS/UFPB, under the protocol number 0569/15 and registered in clinical trials under NCT 02846025. 


\section{Experimental protocol}

After the eligibility criteria were assessed, the women were instructed to maintain the same weight, eating habits, and levels of physical activity that were found during the baseline evaluation [10] and also received an individual diet plan 1 week before starting the dietary intervention (plateau week). All of the individuals' medical treatments remained unchanged throughout the study. At the end of the study, all participants received nutritional counseling for weight loss.

To calculate energy expenditure, the Dietary Reference Intake (DRI) formulas for maintaining body weight were used. Macronutrients were distributed according to the recommendations of the American Heart Association (AHA) [11], and the calculation and analysis of the nutrients present in the recommended diet were performed using the food equivalent system proposed by Costa [12]. The diet contained the following: carbohydrates: 45-65\% (recommended level of 55\%), protein: $10-35 \%$ (recommended level of 15\%), and total fat: $25-35 \%$ (recommended level of 30\%).

In the second week of the study, participants were randomized into four groups: group 1 (G1), in which subjects received $300 \mathrm{~g}$ of vegetables and legumes containing on average $191 \mu \mathrm{g} /$ day of folate and 1 hazelnut oil capsule (25 g); group 2 (G2), in which the subjects received $300 \mathrm{~g}$ of vegetables and legumes containing, on average, $191 \mu \mathrm{g} /$ day of folate and 1 placebo capsule; group 3 (G3), in which subjects received $300 \mathrm{~g}$ of vegetables and legumes containing on average $90 \mu \mathrm{g} /$ day of folate and 1 hazelnut oil capsule ( $25 \mathrm{~g})$; and group 4 (G4), in which subjects were only followed-up and maintained their regular dietary habits. To reach the folate concentrations planned for each group, the following foods were used: lentils, soybeans, corn, peas, carrots, zucchini, lettuce, chard, beetroot, broccoli, cauliflower, tomato, and cucumber.

The hazelnut oil capsule that was offered was composed basically of monounsaturated fat $(68 \%)$, rich in oleic acid.

Each group consisted of 10 women, who received daily vegetables and legumes containing folate for a total period of 8 weeks.

\section{Nutritional and food assessment}

Weight and height were measured in triplicate, and the average of the three values was used. The BMI was then calculated as the body weight $(\mathrm{kg})$ divided by the squared body height (meters), and the cut-off points recommended by the World Health Organization (WHO) were used [13]. Waist circumference (WC) was used to determine abdominal obesity, with the AHA cut-off point of $\geq 88 \mathrm{~cm}$ [14].

To evaluate the regular food intake of the individuals, two 24-h dietary recalls (24HR) were performed, with a 15-day interval from the beginning of the intervention. The 24HR aimed to determine the dietary habits of the individuals and thus define the menu that would be implemented and to compare the intake at the end of the study. After the plateau week, a third $24 \mathrm{HR}$ was performed to check adherence to the nutritional counseling.

At the end of the 8 weeks of intervention, a fourth $24 \mathrm{HR}$ was performed to analyze the regular intake of calories and nutrients to determine whether the subjects adhered to the recommendations for the change in food intake in general and in folate intake after intervention.

To complete the $24 \mathrm{HR}$, a food photograph album with household measures was used and was based on the actual weight of the average food intake validated for this population, thus minimizing possible biases of this method $[15,16]$.

The foods were analyzed by the nutrition software Dietwin, and the multiple source method (MSM) was used to estimate the regular intake of the individual from repeated measurements in a determined period; the variation in intake was not affected by the method [17].

\section{Biochemical analysis}

The biochemical analyses were performed twice: during the selection of the participants and after the end of the nutritional intervention. In both analyses, the levels of total cholesterol (TC) and its fractions (low-density lipoprotein (LDL) and high-density lipoprotein (HDL)), triglycerides, malondialdehyde (MDA), total antioxidant capacity (TAC), homocysteine, and vitamin B12 were measured. The blood samples were collected after a 12$\mathrm{h}$ fast at home, using sterile vacuum tubes with and without anticoagulant, according to the guidelines for the use of sharp materials.

Lipid profile concentrations were determined using the turbidimetry method using a Labmax 240 premiumLabtest automated biochemical analyzer. For analysis of antioxidant activity through the plasma MDA and serum TAC, we used a previously described protocol [18]. Homocysteine levels were quantified using the highperformance liquid chromatography (HPLC) method [19]. The serum concentrations of folic acid and vitamin B12 were measured by chemiluminescence and an electrochemiluminescence immunoassay, respectively.

\section{Methylation levels}

DNA methylation in genomic DNA from blood was quantified at the CarMeN/Universite de Lyon1-France Laboratory.

The blood was chosen for the analysis as it is a metabolically active tissue, with an important role in the adverse inflammatory and vascular consequences of adiposity, and is widely used for clinical diagnostic purposes [20]. 
Table 1 Primers used to analyze the methylation status

\begin{tabular}{llll}
\hline Gene & \multicolumn{2}{l}{ Primers } & Annealing temperature \\
\hline ADRB3 & F & $5^{\prime C C C T C C T T C T I T C C C T A C C G 3 ' ~}$ & $64^{\circ} \mathrm{C}$ \\
& R & 5'TGGTCTGGAGTCTCGGAGTC3' & \\
\end{tabular}

$F$ forward primer, $R$ reverse primer

Whole blood was obtained before and after the intervention. The blood samples were obtained at 08:30 am \pm 10 ( $\mathrm{min}$ ) in all patients and in both conditions (before and after intervention) to avoid a potential sampling time effect. DNA was isolated with a QIAamp DNA Mini kit (Qiagen, Valencia, CA, USA), and the DNA concentrations of the samples were determined using a Qubit ${ }^{\circledR}$ dsDNA HS Assay Kit. Genomic DNA was modified by bisulfite and amplified by AmpliTaq Gold ${ }^{\circledR}$ DNA Polymerase (Applied Biosystems, California 94404, USA) using the sequence described in Table 1. The PCR program consisted of an initial enzymatic activation at $95^{\circ} \mathrm{C}$ for $10 \mathrm{~min}$, followed by 50 cycles of $45 \mathrm{~s}$ at $95{ }^{\circ} \mathrm{C}, 45 \mathrm{~s}$ at $60{ }^{\circ} \mathrm{C}$ and $45 \mathrm{~s}$ at $72{ }^{\circ} \mathrm{C}$ and a final extension at $72{ }^{\circ} \mathrm{C}$ for $10 \mathrm{~min}$.

The analysis of the results was performed with PyroMark Q24 software (Qiagen, Hilden, Germany).

\section{Statistical analysis}

For proposed objectives, a descriptive analysis of the characteristics of the sample was performed first using the mean and standard deviation before and after intervention. Data were assessed for normality using the Lilliefors test, a modification of the Kolmogorov-Smirnov test [21]. Statistical analysis was performed with the STATA 13 software. To analyze the initial and final values after dietary intervention, the normal variables were analyzed using Student's $t$ test. Moreover, analysis of variance (ANOVA) was used to compare the effects of the intervention between the four groups, and the relationship of methylation levels per group was evaluated by simple linear regression.

All analyses were performed with log10-transformed methylation percentages to obtain normality. For all statistical analyses, values of $p<0.05$ were considered significant.

\section{Results}

The study included 40 women classified as overweight or obese. Means and standard deviations are presented in Table 2; the anthropometric measurements, DNA promoter methylation, and biochemical parameters were evaluated before and after the dietary intervention.

It was observed, after intervention in the total sample, lower methylation levels of the $A D R B 3$ gene and increase in HDL-C, MDA, and TAC values.

Table 3 shows the methylation levels and food intake distributed by intervention group, with values for the following nutrients: folate, total fat, saturated fat, monounsaturated fat, polyunsaturated fat, and trans fat. Regarding weight, the groups that had lower levels of methylation had lower weights.

For the calorie intake, no difference was obtained even with dietary intervention, and individuals did not consume the recommended values of folate $(400 \mu \mathrm{g} / \mathrm{day}$, according to the DRI). For total fat, the groups were within the recommended limit (25-30\% fat corresponding to energy consumed); for saturated fat, all subjects consumed levels above the recommended (the guidelines recommend a saturated fat intake $<10 \%)$; for monounsaturated fat, the groups consumed an adequate amount (>15\%), with the exception of group 4; for polyunsaturated fat,

Table 2 Anthropometric characteristics, methylation level, lipid profile and oxidative stress of women before and after intervention

\begin{tabular}{|c|c|c|c|c|c|}
\hline \multirow[t]{2}{*}{ Parameter } & \multicolumn{2}{|c|}{ Before intervention } & \multicolumn{2}{|c|}{ After intervention } & \multirow[b]{2}{*}{$p$ value } \\
\hline & Mean & SD & Mean & SD & \\
\hline Weight (kg) & 77.7 & 14.1 & 74.4 & 14 & 0.4013 \\
\hline Height (m) & 1.59 & 1.1 & 1.59 & 1.1 & - \\
\hline BMI $\left(\mathrm{kg} / \mathrm{m}^{2}\right)$ & 30.5 & 5.3 & 29.2 & 5.1 & 0.3792 \\
\hline WC (cm) & 0.94 & 0.12 & 0.90 & 0.12 & 0.3015 \\
\hline $\mathrm{HC}(\mathrm{cm})$ & 1.14 & 0.12 & 1.01 & 0.11 & 0.2288 \\
\hline Waist-to-height ratio (WHtR; cm/m) & 0.59 & 0.8 & 0.57 & 0.7 & 0.3471 \\
\hline Methylation level (\%) & 42.2 & 18.1 & 29.1 & 14.1 & $0.0006^{*}$ \\
\hline Total cholesterol (mg/dl) & 201.6 & 46.2 & 194.8 & 48.1 & 0.5818 \\
\hline $\mathrm{HDL}-\mathrm{C}(\mathrm{mg} / \mathrm{dl})$ & 44.3 & 9.6 & 50.7 & 9.2 & $0.0118^{*}$ \\
\hline LDL-C (mg/dl) & 122.7 & 43.7 & 119.9 & 40.1 & 0.8103 \\
\hline Triglycerides (mg/dl) & 146.7 & 80.6 & 150.5 & 67.7 & 0.8462 \\
\hline MDA & 3.2 & 0.9 & 4 & 0.8 & $0.0029^{*}$ \\
\hline TAC (\%) & 41 & 13 & 53 & 12 & $0.0005^{*}$ \\
\hline
\end{tabular}


Table 3 Methylation levels of the ADRB3 gene, anthropometric data, and regular food intake of women of the post-intervention groups

\begin{tabular}{|c|c|c|c|c|c|}
\hline Variables & $\begin{array}{l}\text { Group } 1 \\
\text { Mean } \pm \text { SD }\end{array}$ & $\begin{array}{l}\text { Group } 2 \\
\text { Mean } \pm \text { SD }\end{array}$ & $\begin{array}{l}\text { Group } 3 \\
\text { Mean } \pm \text { SD }\end{array}$ & $\begin{array}{l}\text { Group } 4 \\
\text { Mean } \pm \text { SD }\end{array}$ & $p$ value \\
\hline Methylation levels (\%) & $25.3 \pm 5.2$ & $34.7 \pm 3.5$ & $18.1 \pm 2.6$ & $38.3 \pm 3.5$ & $0.0030^{*}$ \\
\hline Weight & $70.15 \pm 2.93$ & $80.56 \pm 6 ; 60$ & $73.48 \pm 2.08$ & $75.91 \pm 2.62$ & 0.3207 \\
\hline Calories & $1444.1 \pm 114.5$ & $1512.8 \pm 67.7$ & $1454.8 \pm 100.1$ & $1637.2 \pm 100.6$ & 0.4863 \\
\hline Folate & $311.2 \pm 7.1$ & $335.4 \pm 9.5$ & $170.1 \pm 14.0$ & $96.4 \pm 2.05$ & $0.000^{*}$ \\
\hline Total fat (g) & $48.9 \pm 3.57$ & $42.9 \pm 2.61$ & $49.57 \pm 4.36$ & $43.64 \pm 4.1$ & 0.4667 \\
\hline Total fat (\%) & $31.06 \pm 1.84$ & $25.5 \pm 1.17$ & $31.4 \pm 2.92$ & $24.2 \pm 1.89$ & $0.0037^{*}$ \\
\hline Saturated fat (g) & $21.48 \pm 2.22$ & $21.32 \pm 2.0$ & $26.6 \pm 1.91$ & $19.24 \pm 1.7$ & 0.0748 \\
\hline Saturated fat (\%) & $13.8 \pm 1.56$ & $12.6 \pm 1.08$ & $16.9 \pm 1.41$ & $11.3 \pm 1.58$ & 0.0551 \\
\hline Monounsaturated fat (g) & $33.6 \pm 1.46$ & $14.2 \pm 0.41$ & $36.02 \pm 1.61$ & $26.41 \pm 2.98$ & $0.0000^{*}$ \\
\hline Monounsaturated fat (\%) & $21.6 \pm 1.26$ & $15.3 \pm 2.20$ & $23.1 \pm 1.51$ & $8.6 \pm 0.45$ & $0.0000^{*}$ \\
\hline Polyunsaturated fat (g) & $12.81 \pm 1.7$ & $6.76 \pm 0.58$ & $19.51 \pm 1.66$ & $9.21 \pm 0.95$ & $0.0000^{*}$ \\
\hline Polyunsaturated fat (\%) & $8.14 \pm 0.96$ & $5.3 \pm 0.74$ & $12.4 \pm 1.34$ & $4.05 \pm 0.31$ & $0.0000^{*}$ \\
\hline Trans fat $(\mathrm{g})$ & $0.58 \pm 0.1$ & $0.54 \pm 0.08$ & $0.55 \pm 0.08$ & $0.53 \pm 0.11$ & 0.9859 \\
\hline
\end{tabular}

groups 2 and 4 did not reach the recommended amount (> 10\%).

Group 3 showed a decrease in methylation levels after the intervention (Table 4). Regarding weight, hip circumference and BMI, no significant differences were obtained between the groups (data not shown). However, WC was $1.2 \mathrm{~cm}$ lower in group 3 than in the other groups, and waist-to-height ratio (WHtR) decreased by $7.92 \mathrm{~cm} / \mathrm{m}$.

Regarding the lipid profile, the values of cholesterol and triglycerides did not show significant differences between the intervention groups (data not shown). However, for the LDL-C values, a decrease of 54.34, 50.32, and $54.78(\mathrm{mg} / \mathrm{dL})$ was observed in groups 1,2 , and 3, respectively. For oxidative stress, group 2 presented an increase in TAC $(p=0.018)$, and MDA increased in group $1(p=0.034)$.

Table 5 shows that the folate intake was highest in group 1. For fat intake, group 1 had the greatest decrease in total fat intake, and group 3 had the highest intake of saturated, monounsaturated, and polyunsaturated fats.

Comparing the results by group before and after intervention showed that there was a significant statistical difference in the methylation levels between groups 2 and 3 and in TAC between groups 1 and 3 (Table 6).

Table 7 shows the results of the test that was performed to compare the post-intervention groups, and it was observed that when groups 2 and 3 were obtained, differences in methylation levels $(p=0.0016)$ were observed, or in other words, group 2 had a higher mean of methylation.

As for the other variables, we observed differences between the means of HDL-C values, in groups 1 and 2 ( $p$ value $=0.0187)$ and in groups 1 and $3(p$ value $=0.0158)$, that is, group 1 presented a higher level of HDL, post-intervention.

\section{Discussion}

In the present study, the dietary intervention with various quantities of folate from vegetables that were close to (but lower than) the DRI, as well as with adequate amounts of monounsaturated fatty acids from the hazelnut oil capsule, did not cause a statistically significant weight loss in the total sample of overweight and obese women; the dietary intervention followed the guidelines for weight maintenance. The results also showed a reduction in the methylation levels of the $A D R B 3$ gene and an increase in the HDL-C values, as well as a decrease in the MDA and an increase in TAC, with both of the latter values being used to evaluate oxidative stress.

The most relevant result was found in group 3 (folate: $90 \mu \mathrm{g} /$ day + hazelnut oil capsule) after the intervention, when the methylation levels decreased (18.1\%). According to Jacobsen [22], values below $25 \%$ are considered low levels of methylation (Table 1).

For weight, the women in groups 1 and 3 had lower weight and lower methylation levels. The proteins encoded by $A D R B 3$ genes belong to the family of betaadrenergic receptors, which mediate the catecholamineinduced activation of adenylate cyclase through the action of $\mathrm{G}$ proteins. These receptors are located in adipose tissue and are involved in energy homeostasis through the mediation of lipolysis and thermogenesis rate. Thus, the genes encoding these receptors are interesting candidates to partially explain the genetic predisposition for obesity in humans [23, 24].

For the dietary intake of folate, total fat and fat fractions evaluated for each intervention group, group 2 consumed a greater daily amount of folate. For fat, groups 1 and 3 consumed higher levels of monounsaturated and polyunsaturated fat, and this difference was statistically significant. 
Table 4 Simple regression analysis of methylation levels, anthropometric measurements, lipid profile, and oxidative stress for the different intervention groups

\begin{tabular}{|c|c|c|c|c|}
\hline \multicolumn{5}{|c|}{ Simple regression } \\
\hline \multicolumn{5}{|c|}{ Methylation levels } \\
\hline & Coefficient & $95 \% \mathrm{Cl}$ & $t$ statistics & $p$ value \\
\hline Group 1 & -0.13 & $-0.24 \pm-0.02$ & -2.37 & $0.023^{*}$ \\
\hline Group 2 & -0.03 & $-0.14 \pm 0.07$ & -0.66 & 0.514 \\
\hline Group 3 & -0.20 & $-0.31 \pm-0.09$ & -3.69 & $0.001^{*}$ \\
\hline \multicolumn{5}{|l|}{ Waist } \\
\hline & Coefficient & $95 \% \mathrm{Cl}$ & t statistics & $p$ value \\
\hline Group 1 & -3.8 & $-13.32 \pm 5.72$ & -0.81 & 0.424 \\
\hline Group 2 & -1.6 & $-11.12 \pm 7.92$ & -0.34 & 0.735 \\
\hline Group 3 & -1.2 & $-21.52 \pm-2.47$ & -2.55 & $0.015^{*}$ \\
\hline \multicolumn{5}{|l|}{ WHtR } \\
\hline & Coefficient & $95 \% \mathrm{Cl}$ & t statistics & $p$ value \\
\hline Group 1 & -1.77 & $-8.35 \pm 4.80$ & -0.55 & 0.580 \\
\hline Group 2 & -0.65 & $-7.23 \pm 5.92$ & -0.20 & 0.841 \\
\hline Group 3 & -7.92 & $-14.50 \pm-1.35$ & -2.44 & $0.020^{*}$ \\
\hline \multicolumn{5}{|l|}{ LDL } \\
\hline & Coefficient & $95 \% \mathrm{Cl}$ & $t$ statistics & $p$ value \\
\hline Group 1 & -54.34 & $-90.78 \pm-17.9$ & -3.02 & $0.005^{*}$ \\
\hline Group 2 & -50.32 & $-86.76 \pm-13.87$ & -2.80 & $0.008^{*}$ \\
\hline Group 3 & -54.78 & $-91.22 \pm-18.33$ & -3.05 & $0.004^{*}$ \\
\hline \multicolumn{5}{|l|}{$\mathrm{HDL}$} \\
\hline & Coefficient & $95 \% \mathrm{Cl}$ & $t$ statistics & $p$ value \\
\hline Group 1 & 16.6 & $9.24 \pm 23.95$ & 4.58 & $0.000 *$ \\
\hline Group 2 & 6.5 & $-0.85 \pm 13.85$ & 1.79 & 0.081 \\
\hline Group 3 & 6.9 & $-0.45 \pm 14.25$ & 1.90 & 0.065 \\
\hline \multicolumn{5}{|l|}{ TAC } \\
\hline & Coefficient & $95 \% \mathrm{Cl}$ & t statistics & $p$ value \\
\hline Group 1 & 0.07 & $-0.36 \pm 0.17$ & 1.32 & 0.195 \\
\hline Group 2 & 0.13 & $0.02 \pm 0.23$ & 2.48 & $0.018^{*}$ \\
\hline Group 3 & 0.03 & $-0.07 \pm 0.13$ & 0.56 & 0.577 \\
\hline \multicolumn{5}{|l|}{ MDA } \\
\hline & Coefficient & $95 \% \mathrm{Cl}$ & $t$ statistics & $p$ value \\
\hline Group 1 & 0.75 & $0.06 \pm 1.43$ & 2.21 & $0.034^{*}$ \\
\hline Group 2 & 0.43 & $-0.27 \pm 1.13$ & 1.23 & 0.228 \\
\hline Group 3 & 0.31 & $-0.38 \pm 0.99$ & 0.91 & 0.367 \\
\hline
\end{tabular}

The women in group 3 also had greater decreases in WC, WHtR, and LDL-C levels. According to Singh [25], BMI, WC, and waist-to-hip ratio are considered methods to distinguish between global obesity (measured by BMI) and central adiposity (measured by WC and waist-to-hip ratio) because a study of the Chinese population demonstrated the impact of fat distribution (subcutaneous and
Table 5 Simple regression analysis of the regular intake of folate, total fat, and fat fractions for the different intervention groups

\begin{tabular}{lllll}
\hline Simple regression & & & \\
\hline Folate & & & & \\
& Coefficient & $95 \% \mathrm{Cl}$ & $t$ statistics & $p$ value \\
Group 1 & 195.7 & $158.4 \pm 233.1$ & 10.62 & $0.000^{*}$ \\
Group 2 & 181.6 & $143.4 \pm 219.8$ & 9.63 & $0.000^{*}$ \\
Group 3 & 107.5 & $69.29 \pm 145.7$ & 5.7 & $0.000^{*}$ \\
Total Fat & & & & \\
& Coefficient & $95 \% \mathrm{Cl}$ & $t$ statistics & $p$ value \\
Group 1 & -4.38 & $-9.87 \pm 1.10$ & -1.62 & 0.114 \\
Group 2 & -6.85 & $-12.46 \pm-1.23$ & -2.47 & $0.018^{*}$ \\
Group 3 & -7.84 & $-13.45 \pm-2.22$ & -2.83 & $0.008^{*}$ \\
Saturated fat & & & & \\
& Coefficient & $95 \% \mathrm{Cl}$ & $t$ statistics & $p$ value \\
Group 1 & 2.24 & $-3.47 \pm 7.95$ & 0.8 & 0.432 \\
Group 2 & 2.08 & $-3.62 \pm 7.79$ & 0.74 & 0.463 \\
Group 3 & 7.4 & $1.68 \pm 13.11$ & 2.63 & $0.013^{*}$ \\
Monounsaturated fat & & & \\
Golyunsaturated fat & Coefficient & $95 \% \mathrm{Cl}$ & $t$ statistics & $p$ value \\
Group 1 & 7.19 & $1.85 \pm 12.52$ & 2.73 & $0.010^{*}$ \\
Group 2 & -12.21 & $-17.54 \pm-6.87$ & -4.64 & $0.000^{*}$ \\
Group 3 & 9.61 & $4.27 \pm 14.94$ & 3.65 & $0.001^{*}$ \\
Group 1 & 3.6 & $1.85 \pm 12.52$ & 1.93 & 0.061 \\
Group 3 & 10.3 & $-17.54 \pm-6.87$ & -1.32 & 0.195 \\
\hline & & $4.27 \pm 14.94$ & 5.54 & $0.000^{*}$ \\
\hline
\end{tabular}

visceral) [25], with $A D R B 3$ mainly being expressed in visceral adipose tissue [26].

Studies of the ADRB3 gene are still scarce in the literature. Such studies show that this gene plays an important role in the regulating lipolysis in the brown and white adipose tissue of humans that provide free fatty acids for thermogenesis. Additionally, there is indirect evidence that $A D R B 3$ may participate in the regulation of body weight in humans [27], suggesting that epigenetic changes in the locus of the $A D R B 3$ gene may be involved in the development of obesity and its associated metabolic complications [28].

There is some evidence for epigenetic parameters related to metabolic diseases that support a relationship between genes and the environment. This type of relationship between genes and environment, epigenetics and metabolic disorders may influence the epigenome and may be one reason for the development of obesity $[29,30]$.

Dietary factors have been reported to affect methylation levels, and some genes such as MC4R and Leptin, 
Table 6 Analysis of methylation levels, waist, WHtR, lipid profile, and oxidative stress, by group before and after intervention

\begin{tabular}{|c|c|c|c|c|c|c|c|c|}
\hline \multirow[t]{2}{*}{ Variables } & \multicolumn{2}{|c|}{ Group 1} & \multicolumn{2}{|c|}{ Group 2} & \multicolumn{2}{|c|}{ Group 3} & \multicolumn{2}{|c|}{ Group 4} \\
\hline & Before & After & Before & After & Before & After & Before & Afte \\
\hline Methylation levels (\%) & 41 & 25 & $55^{a}$ & $34^{a}$ & $35^{\mathrm{b}}$ & $18^{\mathrm{b}}$ & 42 & 38 \\
\hline Waist & 0.95 & 0.92 & 0.97 & 0.95 & 0.9 & 0.84 & 0.96 & 0.96 \\
\hline $\mathrm{WHtR}$ & 0.60 & 0.59 & 0.61 & 0.60 & 0.55 & 0.52 & 0.60 & 0.60 \\
\hline LDL-C & 101.7 & 109.66 & 125.4 & 113.7 & 114.5 & 109.22 & 169 & 164 \\
\hline $\mathrm{HDL}-\mathrm{C}$ & 49.6 & 57.8 & 43 & 47.7 & 40.6 & 48.1 & 38.9 & 41.2 \\
\hline TAC (\%) & $35^{c}$ & $53^{c}$ & $41^{d}$ & $59^{d}$ & 46 & 49 & 40 & 46 \\
\hline MDA & 3.45 & 4.2 & 3.14 & 3.87 & 3.03 & 3.76 & 3.23 & 3.45 \\
\hline
\end{tabular}

${ }^{\mathrm{a}}$ Significant difference between before and after intervention, $p=0.003$

${ }^{\mathrm{b} S i g n i f i c a n t}$ difference between before and after intervention, $p=0.007$

'Significant difference between before and after intervention, $p=0.000$

${ }^{\mathrm{d}}$ Significant difference between before and after intervention, $p=0.001$

have already been reported to alter the methylation patterns that result from a high-fat diet [25]. In the present study, the women with the highest intake of monounsaturated fat were those in groups 1 and 3; these women also had lower levels of methylation. In contrast, group 3 had the highest intake of polyunsaturated fat and the lowest level of methylation, suggesting that a diet rich in polyunsaturated fat would be more effective in altering the methylation patterns of genes such as ADRB3.

Nutrients can modify physiological and pathological processes through the expression of altered genes, and epigenetic modifications are considered a key mechanism underlying the effects of nutrition on gene expression. Polyunsaturated fatty acids, such as omega- 3 , work by reducing body fat and by improving pathological parameters [31]. Another beneficial effect of polyunsaturated fatty acids is their regulation of the synthesis and oxidation of fatty acids. That is, consuming the recommended levels of monounsaturated and polyunsaturated fatty acids is suggested also because doing so will lower the methylation levels of the $A D R B 3$ gene.

The lipid profile is associated with obesity and may be altered in individuals who are classified as overweight and obese. Guay reported that the ADRB3 gene is associated with dyslipidemia [27]; dyslipidemia is characterized by

Table 7 Comparison of post-intervention groups

\begin{tabular}{llll}
\hline & $\begin{array}{l}\text { Group } 1 \times 2 \\
p \text { value }\end{array}$ & Group $1 \times 3$ & Group $2 \times 3$ \\
\hline Methylation levels (\%) & 0.1558 & 0.2361 & $0.0016^{*}$ \\
Waist & 0.1671 & 0.3672 & 0.3205 \\
WHtR & 0.7752 & 0.0581 & 0.0551 \\
LDL-C & 0.7989 & 0.9826 & 0.8427 \\
HDL-C & $0.0187^{*}$ & $0.0158^{*}$ & 0.9217 \\
TAC & 0.1940 & 0.4943 & 0.1436 \\
MDA & 0.4283 & 0.2982 & 0.7242 \\
\hline$P<0.005$ & & &
\end{tabular}

${ }^{*} p<0.005$ increased blood levels of LDL-C and triglycerides and reduced levels of HDL-C [32]. Group 1 showed the highest increase in HDL-C levels, and groups 1 and 3 had the greatest decrease in LDL-C values. These values may be associated with lower levels of $A D R B 3$ gene methylation. The triglyceride and cholesterol values were not significantly different in the present study.

Group 2 presented the highest levels of methylation and lowest decrease in LDL-C, as well as the lowest increase in HDL-C and the lowest intake of monounsaturated and polyunsaturated fat, which are reported to improve the lipid profile and potentially prevent diet-induced dyslipidemia [32].

Biomarkers related to oxidative stress, such as MDA and TAC, have been rarely studied in terms of their association with the ADRB3 gene in overweight and obese women. However, group 2 had the highest increase in TAC; this group had an intake $(300 \mathrm{~g})$ of vegetables similar to that of the other groups and greater consumption of folate $(191 \mu \mathrm{g})$. Increased plasma TAC values are associated with higher regular intake of fruits, vegetables, and nuts [32].

\section{Conclusions}

In conclusion, this study is the first to demonstrate the beneficial effect of the intake of hazelnut oil capsules on the methylation levels of the $A D R B 3$ gene; however, the group with the highest folate intake was the group with the highest levels of methylation. Group 3 had the lowest methylation levels, the largest reductions in WC, WHtR, LDL-C, and total fat intake and the highest intake of monounsaturated and polyunsaturated fats. The data presented in this study show that the methylation levels were influenced by dietary factors, such as the intake of monounsaturated and polyunsaturated fats, that contributed to the reduction in the methylation levels of the $A D R B 3$ gene. The results of this study may be used in the future for the prevention and management of obesity-related complications. 


\section{Acknowledgements}

We would like to acknowledge the project coordinator, Prof. Dr. Maria José de Carvalho Costa, and her team composed of teachers, master's, doctoral and undergraduate students, and research collaborators (Post-Graduation program in Nutritional Sciences/Federal University of Paraíba).

\section{Funding}

Not applicable.

\section{Availability of data and materials}

The data generated in this study are coordinated by Dr. Maria José de Carvalho Costa.

\section{Authors' contributions}

RPAL contributed to data management, statistical analysis, data interpretation, and writing of the manuscript. RAFN contributed to data acquisition and biochemical tests. RCPL contributed to data management. DCP and NFPdeO coordinated the DNA methylation analyses and were involved in the critical review of the manuscript. EVJ and MdaCRG contributed to the analysis of food consumption. ASdaS contributed to the biochemical analyses. POP, EF-M, HV, $L P$, and $M M$ were involved in the development of the manuscript or in the critical review of relevant intellectual content. ATCA and RMdeM contributed to the study design and statistical analysis. MJdeCC contributed to the study design, statistical analysis, data interpretation, and writing of the manuscript she coordinated data collection and was involved in the development of the manuscript or in the critical review of relevant intellectual content. All authors read and approved the final manuscript.

\section{Ethics approval and consent to participate}

The study was approved by the Research Ethics Committee of the CCS/UFPB, under the protocol number 0569/15, registered in clinical trials under NCT 02846025, and complied the declaration for human research. All subjects gave their written informed consent.

\section{Consent for publication}

Not applicable.

\section{Competing interests}

The authors declare that they have no competing interests.

\section{Publisher's Note}

Springer Nature remains neutral with regard to jurisdictional claims in published maps and institutional affiliations.

\section{Author details}

${ }^{1}$ Graduate Program in Nutritional Sciences, Health Sciences Center (Centro de Ciências da Saúd-CCS), Federal University of Paraíba (Universidade Federal da Paraíba), João Pessoa, Brazil. ${ }^{2}$ Graduate Program in Molecular and Human Biology, Center of Natural and Exact Sciences (Centro de Ciências Exatas da Natureza-CCEN), Federal University of Paraíba, João Pessoa, Brazil. ${ }^{3}$ Graduate Program in Nutritional Sciences, CCS, Federal University of Paraíba, João Pessoa, Brazil. ${ }^{4}$ Graduate Program in Cellular and Molecular Biology CCEN, Federal University of Paraíba, João Pessoa, Brazil. ${ }^{5}$ Department of Economics, Center for Applied Social Sciences (Centro de Ciências Sociais Aplicada-CCSA), Federal University of Paraíba, João Pessoa, Brazil. ${ }^{6}$ Graduate Program in Decision Models in Health, CCEN, Federal University of Paraíba, João Pessoa, Brazil. ${ }^{7}$ Department of Epidemiology, Institute of Social Medicine, State University of Rio de Janeiro (Universidade Estadual do Rio de Janeiro), João Pessoa, Brazil. ${ }^{8}$ University of Lyon 1, CARMEN-Vileurbanne Laboratory, Villeurbanne, France. ${ }^{9}$ Graduate Program in Nutritional and Sport Sciences and Metabolism (Ciências da Nutrição, do Esporte e Metabolismo-CNEM), School of Applied Sciences (Faculdade de Ciências Aplicadas-FCA), State University of Campinas (Universidade Estadual de Campinas-UNICAMP), Campinas, Brazil. ${ }^{10}$ Present Address: Pós-graduação em Ciências da Nutrição, Centro de Ciências da Saúde, NIESN-Núcleo Interdisciplinar de Estudos em Saúde e Nutrição/Universidade Federal da Paraíba, Castelo Branco, João Pessoa, PB 58059-900, Brazil.
Received: 12 June 2017 Accepted: 18 September 2017

Published online: 13 October 2017

\section{References}

1. Lopomo A, Burgio E, Migliore L. Epigenetics of Obesity. Prog Mol Biol Trans Sci. 2016;140:151-84

2. Lopez KN, Knudson JD. Obesity: from the agricultural revolution to the contemporary pediatric epidemic. Congenit Heart Dis. 2012;7:189-99.

3. Ng M, Fleming T, Robinson M, Thomson B, Graetz N, Margono C, et al. Global, regional, and national prevalence of overweight and obesity in children and adults during 1980-2013: a systematic analysis for the Global Burden of Disease Study 2013. Lancet. 2014;384(9945):766-81.

4. Keller M, Hopp L, Liu X, Wohland T, Rohde K, Cancelo R, Klos M, et al. Genome-wide DNA promoter methylation and transcriptome analysis in human adipose tissue unravels novel candidate genes for obesity. Mol Metab. 2017;6(1):86-100.

5. Brettfeld C, Englert S, Aumueller E, Haslberger AG. Genetic and epigenetic interactions in adaptive thermogenesis pathways in association with obesity from a Public Health Genomics perspective. Ital J Public Health. 2012;9:1-18.

6. van Dijk S, Tellam RL, Morrison JL, Muhlhausler BS, Molloy PL. Recent developments on the role of epigenetics in obesity and metabolic disease. Clin Epigenetics. 2015;7:66.

7. Shen W, Wang C, Xia L, Fan C, Dong H, Deckelbaum RJ, Qi, K. Epigenetic modification of the leptin promoter in diet-induced obese mice and the effects of N-3 polyunsaturated fatty acids. Sci Rep. 2014;4:1-8.

8. Fradin D, Boelle PY, Belot MP, Lachaux F, Tost J, Besse C, Deleuze JF, Filippo $\mathrm{G}$, Bougneres P. Genome-wide methylation analysis identifies specific epigenetic marks in severely obese children. Sci Rep. 2017;7:1-8.

9. Manolio TA, et al. Finding the missing heritability of complex diseases. Nature. 2009:461:747-53.

10. Switzeny OJ, Müllner E, Wagner KH, Brath H, Aumüller E, Haslberger AG. Vitamin and antioxidant rich diet increases MLH1 promoter DNA methylation in DMT2 subjects. Clin Epigenetics. 2012;4:1.

11. AHA (American Heart Association). Dietary Guidelines for American. 2010. http://www.heart.org/HEARTORG/. Accessed 01 Apr 2016.

12. COSTA MJCC. Nutrição clínica: uso do sistema de equivalentes na prática dietoterápica. 2rd ed. João Pessoa: Editora da UFPB; 2013.

13. WHO (World Health Organization). Obesity: preventing and managing the global epidemic. Report of a WHO consultation. World Health Organ. 2000:894:11-253.

14. Grundy SM, Cleeman Jl, Daniels SR, Donato KA, Eckel RH, Franklin BA, et al. Diagnosis and management of the metabolic syndrome: an American Heart Association/National Heart, Lung, and Blood Institute scientific statement: Executive Summary. Crit Pathw Cardiol. 2005:4(4):198-203.

15. Asciutti LSR. Manual de porções média em tamanho real baseado no programa dietsys para estudo de base populacional. João Pessoa: Editora da UFPB; 2005.

16. Lima FE, Latorre Mdo R, Costa MJ, Fisberg RM. Diet and cancer in Northeast Brazil: evaluation of eating habits and food group consumption in relation to breast cancer. Cad Saude Publica. 2008;24(4):820-8.

17. MSM. The Multiple Source Method. Departament of Epidemiology of the German Institute of Human Nutrition Potsdam. https://msm.dife.de/tps/ msm/. Accessed 17 Nov 2014.

18. de Medeiros Cavalcante IG, Silva AS, Costa MJ, Persuhn DC, Issa CT, de Luna Freire TL, et al. Effect of vitamin D3 supplementation and influence of Bsml polymorphism of the VDR gene of the inflammatory profile and oxidative stress in elderly women with vitamin D insufficiency: Vitamin D3 megadose reduces inflammatory markers. Exp Gerontol. 2015;66:10-6.

19. Kuo K, Still R, Cale S, Mcdowell I. Standardization (External and Internal) of HPLC Assay for Plasma Homocysteine. Clin Chem. 1997;43(9):1653-5.

20. Siegel S. Estatística não paramétrica para as ciências do comportamento. São Paulo: McGraw-Hill do Brasil; 1977.

21. Jacobsen SC, Brøns C, Bork-Jensen J, et al. Effects ofs hortterm high-fat overfeeding on genome-wide DNA methylation in the skeletal muscle of healthy young men. Diabetologia. 2012;55:3341-9.

22. Chou YC, Tsai CN, Lee YS, Pei JS. Associação de polimorfismos de genes receptores adrenérgicos com obesidade adolescente em Taiwan. Pediatr Int 2012;54(1):111-6.

23. Leonska - Duniec A, Ahmetov II, Zmijewski P. Genetic variants influencing effectiveness of exercise training programmes in obesity - an overview of human studies. Biologie Esporte, 33, 3, 207-214, 2016. 
24. Dhasarathy A, Roemmich JN, Claycombe KJ. Influence of maternal obesity, diet and exercise on epigenetic regulation of adipocytes. Mol Asp Med. 2017;54:37-49.

25. Dunn GA, Bale TL. Maternal high_fat efects on third — generation female body size via the paternla lineage. Endocrinology. 2011;152:2228-36.

26. Guay SP, Brisson D, Lamarche B, Biron S, Lescelleur O, Biertho L, Marceau S, Vohl MC, Gaudet B, Bouchard L. ADRB3 gene promoter DNA nethylation in blood and visceral adipose tissue is associated with metabolic disturbances in men. Epigenomics. 2014;6(1):33-43.

27. D'Angelo CS, Koffmann CP. Copy number variants in obesity-related syndromes: review and perspectives on novel molecular approches. J Obes. 2012;2012:1-16.

28. Kurylowicz A, Jonas M, Lisik W, Jonas M, Wicik ZA, Wierzbicki Z, Chmura A, Puzianowska-kuznicka M. Obesity is associated with a decrease in expression but not with the hypermethylation of thermogenesis-related genes in adipose tissues. J Transl Med. 2015;13(31):1-10.

29. Fall T, Ingelsson E. Genome-wide association studies of obesity and metabolic syndrome. Mol Cell Endocrinol. 2014;382:740-57.

30. Wells JC. The evolutions of human fatness and susceptibility to obesity: an ethological approach. Biol Rev Camb Philos Soc. 2014;81:183-205.

31. Ching - Yang, T.; Chen, Y.J.; Chang, S.; Chen, C.; Chang, P.; Shao - Chun LU. Malondialdehyde mediates oxidized LDL-induced coronary toxicity through the Akt-FGF2 pathway via DNA methylation. J Biomed Sci, 21, 1, 1-11, 2014.

32. Ferrari CKB. Capacidade antioxidante total (CAT) em estudos clínicos, experimentais e nutricionais. J Health Sci Inst. 2010;28(4):307-10.

\section{Submit your next manuscript to BioMed Central and we will help you at every step:}

- We accept pre-submission inquiries

- Our selector tool helps you to find the most relevant journal

- We provide round the clock customer support

- Convenient online submission

- Thorough peer review

- Inclusion in PubMed and all major indexing services

- Maximum visibility for your research

Submit your manuscript at www.biomedcentral.com/submit

) Biomed Central 